\title{
METODOLOGIAS PARA O ENSINO DE ENGENHARIA NO CONTEXTO DA EDUCAÇÃO A DISTÂNCIA: ESTADO DA ARTE
}

\author{
Gisele da Silva Cardoso/ ${ }^{1}$ \\ Patrícia Jantsch Fiuza/2 \\ Robson Rodrigues Lemos ${ }^{3}$
}

\begin{abstract}
Resumo: Este estudo analisa as concepções metodológicas apresentadas em propostas de ensino em cursos de engenharia na modalidade de educação a distância. Para tal, realizouse uma Revisão Sistemática de Literatura, acrescida de uma busca dirigida ao tema. Sob o método de análise descritiva, os artigos selecionados apontaram como principal tendência as metodologias ativas. Essa abordagem direciona o foco do ensino para a aprendizagem do estudante, colocando-o numa posição mais ativa e autônoma em relação a própria aprendizagem. Pode-se concluir que ao estruturar uma proposta de ensino para um curso de engenharia na modalidade de educação a distância, é importante a caracterização dos sujeitos envolvidos no processo de ensino e aprendizagem, assim como a principal teoria de aprendizagem que suportará o processo.
\end{abstract}

Palavras-chave: Educação a Distância. Educação em Engenharia. Graduação. Metodologias de Ensino.

\section{CONCEPTIONS OF LEARNING IN THE CONTEXT OF DISTANCE EDUCATION: CONTRIBUTIONS TO ENGINEERING EDUCATION}

\begin{abstract}
The main goal of this study is to analyse the methodological conceptions presented in educational proposals in engineering courses in the modality of distance education. For that, a systematic review of literature was carried out, including a search in the literature addressed to the theme. Under the method of descriptive analysis, the selected articles pointed out as the main trend the active methodologies. These approaches direct the focus of teaching to student learning, placing it in a more active and autonomous position in relation to learning itself. It can be concluded that by structuring a teaching proposal for an engineering course in the modality of distance education, it is important to characterize the subjects involved in the teaching and learning process as well as the main learning theory that will support the process.
\end{abstract}

Keywords: Distance Education. Education in Engineering. Undergraduate Education. Teaching Methodologies.

\footnotetext{
${ }^{1}$ Universidade Federal de Santa Catarina. Gisele.cardoso@ifsc.edu.br

${ }^{2}$ Universidade Federal de Santa Catarina, Araranguá. Brasil. Patrícia.fiuza@ufsc.br

${ }^{3}$ Universidade Federal de Santa Catarina, Araranguá. Brasil. Robson.lemos@ufsc.br
}

Criar Educação, Criciúma, v. 8, no1, jan/jul 2019.- PPGE - UNESC 
A educação a distância é uma modalidade de ensino que vem crescendo em todo o mundo. No Brasil, não é diferente. Os dados do Censo da Educação Superior 2016 divulgados no fim de agosto de 2017 indicam um aumento de matrículas na casa dos 7,2\%, entre 2015 e 2016. Já as matrículas em cursos presenciais diminuíram 1,2\% em comparação ao mesmo período. (BRASIL, 2016). Mas, apesar da expansão da educação a distância observada no país, tanto nas ofertas de matrículas do setor público, como do setor privado, no âmbito dos cursos de engenharia a educação a distância ainda não é tão consolidada. Segundo o relatório de Análise Setorial da Educação Superior 2017, dentre os 10 cursos de maior volumetria na educação presencial, aparecem duas engenharias: civil em terceiro lugar e engenharia de produção em nono lugar. Já na educação a distância, não há o registro nesse ranking de matrículas em cursos de engenharia. (HOPER, 2017)

Mesmo a área de engenharia não se destacando na oferta de educação a distância, algumas iniciativas já começam a aparecer, como demonstra o Censo do Ensino a Distância (CensoEAD) do ano de 2016, realizado pela Associação Brasileira de Educação a Distância (ABED). Esse documento indica a existência de 76 cursos regulamentados totalmente a distância e 48 cursos regulamentados como semipresencial na área das engenharias. Em relação às matrículas, o Censo EAD 2016 traz o registro de 9.043 matrículas em cursos regulamentados totalmente a distância e 8.831 matrículas em cursos regulamentados como semipresencial na área das engenharias. (ABED, 2016)

Os números indicam que os fatores que caracterizam a modalidade de educação a distância têm atraído os estudantes que buscam o ensino formal no país, e mesmo em áreas mais conservadoras, como a engenharia. Isso porque dentre as principais características da educação a distância está a mediação por meio das tecnologias da informação e comunicação e a flexibilidade de tempo e espaço dos envolvidos no processo de ensino e aprendizagem, ou seja, estudantes e professores ou profissionais de educação (BRASIL, Decreto 9.057 de 25 de maio de 2017).

Para corroborar com o crescimento das matrículas na educação a distância, a aprovação da Portaria do MEC №1.134 de 10 de outubro de 2016, em seu artigo $1^{\circ}$., possibilita que as instituições de ensino superior com no mínimo um curso de graduação reconhecido, já possa introduzir a oferta de disciplina na modalidade a 
distância, desde que esteja incluído na organização pedagógica e curricular de seus cursos de graduação presenciais regularmente autorizados. Essa atualização da legislação flexibiliza muito a oferta do ensino a distância nas instituições, ao mesmo tempo em que provoca as instituições a refletirem sobre o uso de novas metodologias adequadas a essa modalidade. (BRASIL, Portaria do MEC №1.134 de 10 de outubro de 2016).

Diante desse novo cenário do ensino superior no Brasil, este estudo almeja compreender o estado da arte no ensino de engenharia na modalidade de educação a distância, propondo-se a analisar quais as concepções teóricas e/ou metodológicas são apresentadas em propostas de ensino em cursos de engenharia na modalidade de educação a distância.

Para responder à questão proposta, realizou-se o levantamento bibliográfico sobre o tema. O método de pesquisa bibliográfica do tipo Revisão Sistemática de Literatura - RSL - foi realizado em três bases de dados eletrônicas disponíveis no Portal de Periódicos da CAPES e acrescida de uma busca dirigida ao tema nas edições da Revista de Ensino de Engenharia (ABENGE). O propósito dessa busca de dados foi realizar uma pesquisa exploratória, com o objetivo de identificar as concepções teóricas e/ou metodológicas no ensino de engenharia, na modalidade a distância. Os textos selecionados foram categorizados e analisados sob o método de análise descritiva.

Este artigo está organizado da seguinte forma: na segunda seção é apresentada a fundamentação teórica que subsidia este artigo. Em seguida apresenta-se a metodologia utilizada. Na quarta seção são discutidos os resultados e na sequência faz-se a análise dos dados. Por fim são apresentados as considerações finais e os indicativos de trabalhos futuros.

\section{Fundamentos Teóricos da Educação e a Educação a Distância}

Para compreender os motivos que levam a adoção de determinada base teórica ou metodológica no contexto educacional, faz-se necessário uma incursão por alguns conceitos relativos aos processos de ensino e aprendizagem, teorias de aprendizagem e métodos de ensino. Mesmo que analisados sob a ótica das teorias 
tradicionais, deve-se tentar compreender os aspectos que de alguma maneira contribuem com a formação de uma base teórica e metodológica para a educação a distância.

Considerando o ensino como um campo específico da instrução escolar, Libâneo (2013) coloca que o "processo de ensino-aprendizagem é, fundamentalmente, um trabalho pedagógico no qual se conjugam fatores externos e internos. " (LIBÂNEO, 2013, p. 24). Para o autor, a influência externa é aquela proposta na forma de organização consciente da escola e dos professores, como a definição de objetivos, conteúdos e métodos de ensino, e a interna são as condições físicas, psíquicas e socioculturais dos estudantes. Para o autor, o termo metodologia consiste no estudo do método e do conjunto dos "procedimentos de investigação das diferentes ciências quanto aos seus fundamentos e validade, distinguindo-se das técnicas que são as aplicações específicas dos métodos.”. (LIBÂNEO, 2013, p. 54). Nesse sentido, as técnicas, recursos ou meios de ensino são complementares à metodologia.

Segundo Gómez (1998) os processos de ensino e aprendizagem podem ser considerados como o centro da investigação e da prática didáticas na medida em que toda intervenção educativa necessita apoiar-se no conhecimento teórico e prático, oferecido em partes pelas disciplinas que investigam a natureza dos fenômenos envolvidos nos processos educativos (GÓMEZ, 1998, p. 27). As teorias da aprendizagem proporcionam a informação básica para a organização teórica e prática do ensino, mas isoladamente, não contribuem com o processo de aprendizagem. É necessário considerar as complexas redes de intercâmbio social, de interesses, necessidades e intenções que compõem a cultura do meio em que está inserido o estudante. (GÓMEZ, 1998, p. 51).

Partindo-se dos pressupostos teóricos tradicionais, há algumas décadas alguns pesquisadores vem buscando sistematizar os fundamentos teóricos no contexto da educação a distância. Porém, os esforços em definir uma teoria ou metodologia de ensino e aprendizagem que considere a interação entre os sujeitos e o próprio processo de ensino e aprendizagem por meio das tecnologias, tornam-se mais desafiadores, dado o risco tendencioso de apenas transpor-se uma teoria ou 
metodologia com o uso da tecnologia, mas sem considerar as relações entre o estudante e seu meio.

Desde a década de 1960 alguns pesquisadores começaram a tentar sistematizar uma teoria da educação a distância. No trabalho seminal em 1967, Otto Peters já indicava a necessidade de uso de "métodos industriais", que incluíam técnicas de planejamento sistemático, especialização de equipe de trabalho e tecnologias de comunicação modernas, entre outros. Em 1971 Wedemayer, numa abordagem mais "humanística" posiciona-se em relação a independência do estudante, no controle e direcionamento do aprendizado. Depois de mais de uma década de estudos, Michael Moore chegou em 1986 ao que ficou conhecido como Teoria da Interação a Distância (Transactional Distance), cuja ideia básica é que a distância é um fenômeno pedagógico, e não apenas geográfico. (MOORE \& KEARSLEY, 2007, p. 238-239). Os níveis de interação e diálogo relacionado ao tipo de curso ou tecnologia, levará o estudante a ter maior ou menor autonomia, assim, essa teoria é considerada como "o hiato de compreensão e comunicação entre professores e alunos causado pela distância geográfica que precisa ser suplantada por meio de procedimentos diferenciadores na elaboração da instrução e na facilitação da interação. " (MOORE E KEARSLEY, 2007, p. 240).

Nos últimos anos, outros teóricos têm abordado o uso das tecnologias, a relação professor e estudante, relacionamento social nos cursos a distância e os diversos fatores que interferem no aprendizado à distância, e até mesmo reflexões sobre a necessidade de sistematizar uma teoria pedagógica para a educação a distância, como proposto em Serdyukov, (2015). Esse autor coloca que com o reconhecimento da educação online surgiu a demanda de uma pedagogia específica para essa modalidade, já que ainda é a tecnologia que impulsiona a aprendizagem e a classifica, enquanto a "pedagogiaonline" está atrasada. (SERDYUKOV, 2015, p. 62). Segundo o autor, existe entre educadores, principalmente do ensino superior, a crença errônea de que "a tecnologia irá resolver todas as dificuldades", o chamado "tecnocentrismo". Segundo ele, a "superestimação do poder da tecnologia, lamentavelmente, leva à deterioração do "elemento humano" no ensino contínuo e no aprendizado e na subestimação da necessidade de pedagogia sonora e preparação de instrutores de qualidade." (SERDYUKOV, 2015, p. 63). Isso porque os professores 
não percebem a importância da pedagogia em sua prática. $\mathrm{O}$ autor defende que 0 ambiente online deve promover a comunicação, socialização e colaboração e propõe o desenvolvimento de uma 'e-pedagogia', baseada nos pressupostos da Teoria da Aprendizagem Comportamentalista (Skinner), Teoria do Aprendizado Cognitivo (Piaget), Teoria da Aprendizagem Construtiva (Schell \& Janicki, 2012) e Teoria da Aprendizagem Colaborativa (Harasim, 2012). Segundo o autor, a 'e-pedagogia'

\begin{abstract}
"é uma ciência abrangente que integra todas as questões relacionadas à educação on-line, começando com os fundamentos teóricos e abrangendo instituições de ensino superior, sistemas pedagógicos, desenvolvimento pessoal e profissional, princípios de ensino e aprendizagem, abordagens e métodos de ensino; construção de conhecimento no ambiente on-line; características e papéis do aluno e instrutor, funções, disposições e adequação para a aprendizagem; tecnologias educacionais, design de cursos e planejamento de processos. A projeção de pedagogia no processo de aprendizagem como o sistema de aplicações forma a metodologia de ensino e aprendizagem. (SERDYUKOV, 2015, p. 70).
\end{abstract}

Outros pesquisadores também apostam na integração de diferentes abordagens teóricas e metodológicas para fundamentar uma teoria pedagógica em educação a distância, como é o caso de Filatro (2009). Para essa autora, adotar uma postura que valorize a diversidade e os pontos de intersecção entre os conhecimentos historicamente construídos sobre ensino, aprendizagem e o uso das tecnologias educacionais, respeitando-se a coerência teórica interna das teorias, tende a ser o caminho para melhores experiências de aprendizagem na educação a distância. (FILATRO, 2009, p.103).

\title{
Revisão Sistemática de Literatura
}

Quanto à classificação metodológica, este trabalho foi desenvolvido a partir da obra de Patrícia de Sá Freire (2013). Esta pesquisa apresenta uma abordagem qualitativa e é classificada como exploratória. Utiliza o método de pesquisa bibliográfica denominado Revisão Sistemática de Literatura - RSL. Caracteriza-se como um processo de levantamento de dados que leve a identificação de evidências de um tema de pesquisa (FREIRE, 2013, p. 30). Os resultados da RSL realizado neste estudo foram complementados por uma busca dirigida ao tema (FREIRE, 2013, p. 34).

O objetivo desta RSL foi identificar as concepções teóricas e/ou metodológicas no ensino de engenharia, na modalidade de educação a distância. A partir desse 
estudo, pretende-se localizar possíveis tendências e/ou lacunas existentes nessa modalidade. A RSL é realizada a partir de um planejamento que leve a uma busca sistemática de trabalhos acadêmicos que respondam à questão apresentada. Para isso, realizou-se três estágios que consistem no Planejamento, Execução e Análise dos Dados, sob o método de análise descritiva.

Após a formulação da pergunta procedeu-se a definição dos termos de busca: "Distance Education" e na sequência a combinação "Engineering Education". O tipo de produção a ser pesquisado foi "Artigo" (F1). As bases Web of Science e Scopus foram selecionadas por enquadrarem-se na categoria multidisciplinar no portal de Periódicos da CAPES, e a base IEEExplore, por reunir trabalhos de diversas áreas da engenharia. As três fontes selecionadas são, portanto, condizentes com este estudo. Os números extraídos dessa primeira etapa demonstraram um grande volume de produção referente à temática, conforme observado na Tabela 1:

Tabela 1: Resultados 1‥ Etapa 11/08/2017.

\begin{tabular}{|c|c|c|c|}
\hline Termos de Busca & 1. RESULTADOS & & \\
\hline & 2. IEEEXPLORE & 3. WOS & 4. SCOPUS \\
\hline "Distance Education" & 5. 1.611 & 6. 6.042 & 7. 15.998 \\
\hline "Engineering Education" & 8. 311 & 9. 101 & 10. 3.459 \\
\hline F1 (artigos) & 11. 36 & 12. 42 & 13. 934 \\
\hline TOTAL & 14. 36 & 15. 42 & 16. 934 \\
\hline
\end{tabular}

Fonte: Autores (2017)

A partir da pesquisa nas bases de dados eletrônicas, os dados foram exportados para a ferramenta Start ${ }^{4}$ (State of the Art Through Systematic Reviews) versão 3.3. Essa ferramenta foi elaborada pelo Laboratório de Pesquisas em Engenharia de Software do Departamento de Computação da Universidade de São Carlos UFSCAR. Após a importação dos 934 artigos da Scopus, dos 42 artigos da WOS e do cadastro manual de 36 artigos da base IEEExplore, para a ferramenta Start, iniciou-se a execução da Revisão Sistemática, de acordo com as seguintes etapas:

\footnotetext{
${ }^{4}$ A ferramenta Start encontra-se disponível para download em: http://lapes.dc.ufscar.br/resources-and$\underline{\text { downloads/tools }}$
}

Criar Educação, Criciúma, v. 8, no1, jan/jul 2019.- PPGE - UNESC 
Primeira etapa: a ferramenta Start, exige inicialmente um protocolo planejado pelos autores. Com base nesse protocolo, a ferramenta retornou automaticamente como possível de análise 613 artigos.

Segunda etapa: consistiu na exclusão de artigos que não continham os termos de busca (distance education/engineering education) no título, palavras chave e resumo. Os trabalhos não alinhados aos objetivos desta pesquisa, assim como os duplicados, foram rejeitados, obtendo-se 313 artigos válidos.

Terceira etapa: por meio da leitura dos resumos procurou-se extrair os textos que se apresentassem alinhados com essa pesquisa, sendo extraídos 93 artigos. O critério de inclusão foi selecionar trabalhos que explicitassem uma abordagem teórica e/ou metodológica em cursos de engenharia, nível de graduação, na modalidade de educação a distância.

Quarta etapa: A fim de selecionar os trabalhos mais alinhados com a pesquisa, procedeu-se a leitura da seção Introdução e Apresentação dos Resultados/Conclusão dos 93 artigos, considerando os mesmos fatores de inclusão da etapa anterior, resultando em 13 artigos.

A busca dirigida ao tema foi realizada na base de dados da Associação Brasileira de Ensino de Engenharia - ABENGE, que publica regularmente a Revista de Ensino de Engenharia. No campo "Pesquisa" foi inserido apenas o termo educação a distância, já que a revista é específica para o ensino de engenharia. Obteve-se o retorno de 8 artigos, entre os anos de 2006 e 2016, sendo que cinco não estavam alinhados com esse estudo, resultando em 3 textos selecionados. Por fim, obteve-se um portfólio de 16 artigos que foram analisados e categorizados.

Os dados coletados durante a Revisão Sistemática de Literatura foram tratados sob o método de análise descritiva, já que os artigos foram agrupados de forma qualitativa, buscando identificar-se as abordagens teóricas e/ou metodológicas apresentadas.

\section{Apresentação dos Resultados}

As análises foram baseadas nos 16 textos selecionados pelo método de Revisão Sistemática de Literatura. A questão que se pretendeu responder a partir 
dessa análise foi quais as concepções teóricas e/ou metodológicas são apresentadas em propostas de ensino em cursos de engenharia na modalidade de educação a distância. Para isso, buscou-se identificar as concepções metodológicas apresentadas nas propostas de ensino documentados na Tabela 2:

Tabela 2: Portfólio

\begin{tabular}{|c|c|c|c|c|c|}
\hline Ordem & Autores & Ano & País & Modalidade & Abordagem metodológica \\
\hline 1 & H. A. Latchman, et al & 1999 & EUA & Híbrido & Aprendizagem colaborativa \\
\hline 2 & T. Froese, et al & 2001 & Canadá & Hibrido & Aprendizagem ativa \\
\hline 3 & J. Reisslein, et al & 2005 & EUA & Híbrido & Aprendizagem Colaborativa \\
\hline 4 & R.M.F Vargas et al. & 2006 & Brasil & EAD & Aprendizagem Colaborativa \\
\hline 5 & L.M. Brodie e M. Porter & 2008 & Austrália & EAD & $\begin{array}{l}\text { Aprendizagem Baseada em } \\
\text { Problemas }\end{array}$ \\
\hline 6 & B. Barros, et al. & 2008 & Espanha & EAD & Aprendizagem Colaborativa \\
\hline 7 & J. A. Méndez e E. J. González & 2010 & Espanha & Híbrido & $\begin{array}{l}\text { Aprendizagem Baseada em } \\
\text { Problemas }\end{array}$ \\
\hline 8 & J. S. Liang & 2010 & China & EAD & $\begin{array}{l}\text { Aprendizagem Baseada em } \\
\text { Problemas }\end{array}$ \\
\hline 9 & J. A. Méndez e E. J. González & 2011 & Espanha & Híbrido & $\begin{array}{l}\text { Autodeterminação } \\
\text { (motivação/ativa) }\end{array}$ \\
\hline 10 & H. Vargas et al. & 2011 & Espanha & EAD & Aprendizagem social \\
\hline 11 & L. N. Magalhães e L.H.P. Lima & 2012 & Brasil & Híbrido & Design Instrucional \\
\hline 12 & P. Wu et al. & 2013 & Austrália & EAD & $\begin{array}{l}\text { Aprendizagem } \\
\text { (ativa) }\end{array}$ \\
\hline 13 & W. He et al. & 2014 & EUA & Hibrido & $\begin{array}{l}\text { Aprendizagem Flexível } \\
\text { (ativa) }\end{array}$ \\
\hline 14 & F. Luthon, e B. Larroque & 2015 & França & Hibrido & $\begin{array}{l}\text { Aprendizagem baseada em } \\
\text { jogos }\end{array}$ \\
\hline 15 & A.L. Vilela et al. & 2016 & Brasil & Híbrido & Aprendizagem ativa \\
\hline 16 & A. J. Swart & 2016 & $\begin{array}{l}\text { África do } \\
\text { Sul }\end{array}$ & EAD & $\begin{array}{l}\text { Aprendizagem Baseada em } \\
\text { Problemas }\end{array}$ \\
\hline
\end{tabular}

Fonte: Autores (2017) 
O primeiro trabalho que relaciona a educação a distância ao ensino de engenharia, apresentando preocupação com o padrão metodológico é datado de 1999, nas áreas de engenharia elétrica e computação da University of Florida (Estados Unidos da América) (LATCHMAN et al.,1999).

Nos anos seguintes, como apresentado na Tabela 2, é possível observar outros trabalhos, em diversas partes do mundo, que articularam a educação à distância ao ensino de engenharia. Nessa amostra, a maioria dos artigos, 09 ao total, discutem ou apresentam propostas no contexto do ensino hibrido, ou seja, articulando estratégias do ensino presencial com estratégias do ensino a distância.

Embora apenas 3 trabalhos apresentem claramente uma posição em relação as teorias de aprendizagem, sendo Wu et al (2013) e Vargas et al (2006) a concepção da teoria Sociocultural e Barros, Read e Verdejo, (2008) a teoria do construtivismo social; todos os trabalhos selecionados tecem alguma fundamentação em relação a abordagem metodológica adotada, destacando-se as metodologias ativas da aprendizagem.

\section{Metodologias ativas da aprendizagem}

As metodologias ativas da aprendizagem foram referidas com diferentes definições nesta pesquisa (colaborativa, aprendizagem baseada em problemas, ativa, social, design instrucional, e abordagem baseada em jogos digitais). A fim de conseguir agrupá-las, recorreu-se a conceituação de Moran (2015), de que "nas metodologias ativas de aprendizagem, o aprendizado se dá a partir de problemas e situações reais; os mesmos que os alunos vivenciarão depois na vida profissional, de forma antecipada, durante o curso" (MORÁN, 2015, p. 19).

As metodologias ativas presentes nessa amostra destacam um contexto de mediação por meio dos recursos tecnológicos. Nesse sentido, foi necessário tanto a estruturação de material didático usando a internet, como descrito em Froese, Zhu e Bhat (2001), como de recursos que possibilitassem o exercício prático, como em Vargas et al (2011). Em ambas experiências o foco era a melhoria da aprendizagem, melhor eficiência do ensino e suporte para aprendizagem a distância. Porém, os pesquisadores foram percebendo em seus percursos que, para a aprendizagem por 
meio das metodologias ativas serem efetivas, fatores como a motivação dos estudantes deveria ser incentivada, como apresentado em Méndez e Gonzáles (2011) e em He et al (2014).Também, para elaborar bons materiais e recursos, capazes de motivar os estudantes numa perspectiva ativa, Magalhães e Lima (2012) apresentam a metodologia do Design Instrucional como uma alternativa de planejamento de ensino suportado pelas tecnologias da informação e comunicação e com 0 acompanhamento de uma equipe multidisciplinar. Da mesma forma, Wu et al (2013) se ocuparam do design, sistematizando dados significativos para a criação de cursos.

Já em 2016, Vilela, Vilela e Lima (2016) apresentam a implantação de uma disciplina na modalidade de educação a distância para cursos presenciais de engenharia na Escola Politécnica de Pernambuco. A proposta baseia-se na aprendizagem ativa, onde o foco é o próprio estudante. Esse modelo foi desenvolvido considerando-se a importância da comunicação, a atemporalidade e o ambiente virtual de aprendizagem, a partir das estratégias de aprendizagem ativa. Uma outra estratégia que surge como possibilidade de uma metodologia ativa é a aprendizagem baseada em Jogos Digitais, como proposto em Luthon e Larroque (2015).

O método colaborativo de aprendizagem, também considerado uma metodologia ativa, pressupõe a colaboração entre os estudantes durante a execução das tarefas. A preocupação sobre as questões metodológicas que envolvem a aprendizagem hibrida, em uma perspectiva colaborativa já estava presente em Latchman et al (1999), segundo os autores, os estudantes devem ser encorajados a explorar novos caminhos de aprendizagem, a partir de uma abordagem educacional integrada, em que o ensino expositivo e as atividades de aprendizagem ativa sejam combinadas e equilibradas de acordo com seus respectivos objetivos pedagógicos, suas eficiências didáticas e restrições técnicas (LATCHMAN, 1999, p. 252). Em publicações posteriores, no contexto da educação a distância e também do ensino híbrido, as atividades virtuais começaram a ser percebidas como potenciais recursos para facilitar a comunicação e a colaboração, principalmente na criação de redes de aprendizagem. Diversos autores têm assumido essa concepção metodológica, como Barros, Read e Verdejo (2008), Vargas et al (2006) e Reisslein, Seeling e Reisslen (2005). Estes últimos consideram que o processo de aprendizagem acontece pela integração de novas informações, levando em consideração os conhecimentos 
prévios e os processos de seleção, organização e integração desses conhecimentos. Neste sentido, a aprendizagem colaborativa exige que os estudantes organizem seu conhecimento, de forma que o resultado contribua para que outro estudante, também realize esse processo.

Uma outra metodologia que parece agradar ao ensino de engenharia é a aprendizagem baseada em problema, o PBL, do inglês Problem Based Learning, como apresentado em Brodie e Porter (2008), Liang (2010) e Méndez e González (2010). Esse método exige dos estudantes capacidade de flexibilidade em relação a mudanças e novas técnicas, formulação e solução de problemas, capacidade de análise, avaliação e síntese, inovação e criatividade, entre outras. Porém, há pesquisadores que encontraram algumas dificuldades nesse método, como é o caso de Swart (2016). O autor coloca que o PBL é uma metodologia que tem o potencial de ajudar os alunos a adquirir os conhecimentos e as habilidades necessárias na indústria, porém, na sua experiência o PBL foi o método que apresentou os maiores desafios e o que os estudantes tiveram maiores dificuldades (SWART, 2016, p. 103).

\section{Discussão dos Resultados}

Como apresentado na seção anterior, existe na literatura um volume expressivo de publicações envolvendo cursos de engenharia na modalidade de educação a distância. Porém, a maioria dos trabalhos foi excluída justamente por não apresentar uma abordagem teórica e/ou metodológica em suas propostas. Grande parte dos artigos constituíram-se de relatos de experiências, sem refletir nas implicações pedagógicas e metodológicas dos estudos apresentados. Como o ensino a distância pressupõe a mediação das tecnologias da informação e comunicação, acaba sendo esse o foco da maioria das pesquisas, e não os processos de ensino e aprendizagem, devidamente fundamentados por teorias e métodos advindo do campo da pedagogia, já que cabe a pedagogia criar um conjunto de condições metodológica para viabilizar o processo de ensino e aprendizagem (LIBÂNEO, 2013, p.23).

Com o objetivo de encontrar experiências na literatura que explicitassem as concepções teóricas e/ou metodológicas em propostas de ensino em cursos de engenharia na modalidade de educação a distância, acabou-se por constituir um 
portfólio de 16 artigos, oriundo de uma revisão sistemática de literatura, que indicou como tendência as metodologias ativas da aprendizagem.

Em relação aos processos de ensino e aprendizagem, as metodologias ativas, em suas diferentes denominações, apontam a questão da colaboração, envolvimento, autonomia e motivação entre os estudantes. As propostas analisadas também indicam que o foco do ensino é a aprendizagem do estudante, colocando-o numa posição mais ativa e autônoma em relação a sua aprendizagem. As pesquisas apontam os desafios em promover a participação dos estudantes nos Ambientes Virtuais e indicam uma grande necessidade de planejamento, motivação, interação para que a aprendizagem aconteça. Da parte dos estudantes, os textos apontam uma avaliação positiva nas inciativas propostas.

Além de uma concepção teórica e/ou metodológica é necessário que uma proposta para a educação a distância considere também os recursos e as ferramentas disponíveis para o processo de ensino e aprendizagem. O mais usual nas engenharias é o uso de ambientes virtuais de aprendizagem que às vezes suportam outros recursos, como por exemplo, laboratórios remotos ou virtuais. Esses ambientes devem ser organizados para que a colaboração aconteça da forma mais efetiva possível. Em relação aos ambientes virtuais de aprendizagem, parece consenso também que quanto mais familiarizados e adaptados com a ferramenta, melhores serão os resultados da aprendizagem dos estudantes. Os ambientes precisam favorecer a comunicação e a interação dos estudantes, e destes com professores e monitores ou tutores.

Aos professores cabe compreender que a educação a distância não é simplesmente a transposição do ensino tradicional para o virtual. Muito pelo contrário, ela requer reflexão, planejamento, diálogo com diferentes envolvidos no processo. Manter uma equipe multidisciplinar talvez não seja viável em muitas instituições, porém, se há o interesse em promover o ensino a distância, é necessário encontrar formas de viabilizar essa modalidade, mesmo com equipe reduzida.

\section{Considerações Finais e Trabalhos Futuros}

Com o crescimento da educação a distância no Brasil e no mundo, propiciado principalmente pelo avanço significativo das tecnologias, surge a necessidade de se Criar Educação, Criciúma, v. 8, no1, jan/jul 2019.- PPGE - UNESC 
repensar os métodos de ensino, principalmente na formação superior. Considerando que algumas iniciativas já estão sendo tomadas no âmbito nacional, como a atualização da legislação pertinente ao tema, é possível que nos próximos anos, a flexibilidade concedida pela legislação às instituições de ensino superior, impulsione as áreas mais tradicionais a explorarem os recursos da educação a distância.

Embora haja um volume expressivo de publicações envolvendo cursos de engenharia com um viés em educação a distância, a maioria dos artigos não apresenta uma ancoragem metodológica em suas propostas. Para que uma mudança de concepção de ensino ou formação de engenharia aconteça e reflita de fato no ensino, é necessário que um projeto mais amplo seja discutido com a comunidade acadêmica, considerando-se as atuais necessidades de formação da área e as mudanças nos paradigmas educacionais, principalmente, em relação à educação a distância.

Além de uma concepção teórica e/ou metodológica é necessário que uma proposta para a educação a distância considere também os recursos e as ferramentas disponíveis para o processo de ensino e aprendizagem. O mais usual nas engenharias é o uso de ambientes virtuais de aprendizagem que às vezes suportam outros recursos, como por exemplo, laboratórios remotos ou virtuais. Esses ambientes devem ser organizados para que a colaboração aconteça da forma mais efetiva possível. Em relação aos ambientes virtuais de aprendizagem, parece consenso também que quanto mais familiarizados e adaptados com a ferramenta, melhores serão os resultados da aprendizagem dos estudantes. Os ambientes precisam favorecer a comunicação e a interação dos estudantes, e destes com professores e monitores ou tutores.

Aos professores cabe compreender que a educação a distância não é simplesmente a transposição do ensino tradicional para o virtual. Muito pelo contrário, ela requer reflexão, planejamento, diálogo com diferentes envolvidos no processo. Manter uma equipe multidisciplinar talvez não seja viável em muitas instituições, porém, se há o interesse em promover o ensino a distância, é necessário encontrar formas de viabilizar essa modalidade, mesmo com equipe reduzida.

\section{Referências}

Criar Educação, Criciúma, v. 8, no1, jan/jul 2019.- PPGE - UNESC 
ABED, Associação Brasileira de Educação a Distância. Censo EAD.BR: relatório analítico da aprendizagem a distância no Brasil 2016. Curitiba: InterSaberes, 2017. Disponível em: http://abed.org.br/censoead2016 Acesso em: 12 outubro 2017.

BARROS, B., READ, T.; VERDEJO, M.F. Virtual collaborative experimentation: An approach combining remote and local labs. IEEE Transactions on Education, Vol. 51, 2008, p. 242-250. Disponível em: <https://www.scopus.com> Acesso em: 11 agosto 2017.

BRASIL. Ministério da Educação. INEP. Instituto Nacional de Estudos e Pesquisas Educacionais Anísio Teixeira. Censo da Educação Superior 2016 Notas Estatísticas. 2016. Disponível em: < http://inep.gov.br> Acesso em: 20 setembro 2017.

BRASIL. Presidência da República. Decreto 9.057 de 25 de maio de 2017. Regulamenta o art. 80 da Lei ㄲo 9.394, de 20 de dezembro de 1996, que estabelece as diretrizes e bases da educação nacional.

BRASIL. Ministério da Educação. Portaria 1.134 de 10 de outubro de 2016. Revoga a Portaria MEC № 4.059, de 10 de dezembro de 2004, e estabelece nova redação para o tema.

BRODIE, L.M. e PORTER, M. Engaging distance and on-campus students in problem-based learning. European Journal of Engineering Education, Vol. 33, 2008, p. 433-443. Disponível em < https://www.scopus.com > Acesso em: 11 agosto 2017.

FILATRO, Andrea. As Teorias pedagógicas fundamentais em EAD. In LITTO, Frederico M; FORMIGA, Marcos. (orgs.) Educação a Distância. 0 estado da arte. São Paulo: Pearson Education do Brasil, 2009. p. 96 - 104.

FREIRE, Patrícia de Sá. Aumente a Qualidade e Quantidade de suas

Publicações Científicas: Manual para elaboração de Projetos e Artigos Científicos. Curitiba, PR: Editora CRV, 2013.

FROESE, T., ZHU, D. e BHAT, S. WWW Courseware in Applied Science: Cases and Lessons. Computer Applications in Engineering Education, Vol. 9, 2001, p. 6377. Disponível em: < https://www.scopus.com > Acesso em: 11 agosto 2017.

GÓMEZ, A.I. Pérez. Os Processos de Ensino-Aprendizagem: Análise Didática das Principais Teorias da Aprendizagem. In SACRISTÁN, J. Gimeno e GÓMEZ, A.I. Pérez Compreender e Transformar o Ensino. 4ㄹ. Ed. São Paulo: Artmed, 1998. Pág. 27-51.

$\mathrm{HE}, \mathrm{W}$. et al. Implementing flexible hybrid instruction in an electrical engineering course: The best of three worlds? Computers and Education. Vol. 81, 2015, p. 5968. Disponível em: < https://www.scopus.com > Acesso em: 11 agosto 2017. 
HOPER EDUCAÇÃO. Análise Setorial da Educação Superior Privada Brasil 2017. Disponível em: <

http://sys.hoper.com.br/webinar/WEBINAR Lancamento AS BR 2017.pdf $>$ Acesso em: 12 outubro 2017.

LATCHMAN H. A. et al. Information technology enhanced learning in distance and conventional education. IEEE Transactions on Education, Vol. 42, 1999, p. 247254. Disponível em < http://ieeexplore.ieee.org > Acesso em: 11 agosto 2017.

LIANG, J.S. Design and implement a virtual learning architecture for troubleshooting practice of automotive chassis. Computer Applications in Engineering Education, Vol. 18, 2010, p. 512-525. Disponível em: < https://www.scopus.com > Acesso em: 11 agosto 2017.

LIBÂNEO, José Carlos. Didática. 2ª . Edição. São Paulo: Cortez, 2013.

LUTHON, F. e LARROQUE, B. LaboREM - A Remote Laboratory for Game-Like Training in Electronics. IEEE Transactions on Learning Technologies, Vol. 8, 2015, p. 311-321. Disponível em: < https://www.scopus.com > Acesso em: 11 agosto 2017.

MAGALHÃES, Luciana Nunes de. LIMA, Luiz Helberth Pacheco de. Proposta de Diretrizes para um Plano de Design Instrucional Dirigido ao Ensino de Flexão Oblíqua em Pilares de Concreto. Revista de Ensino de Engenharia, Vol. 31, n. 2, 2012, p. 17-24. Disponível em: < http://abenge.com.br > Acesso em: 20 setembro 2017.

MÉNDEZ, J.A. e GONZÁLEZ, E.J. A reactive blended learning proposal for an introductory control engineering course. Computers and Education, Vol. 54, 2010, p. 856-865. Disponível em: < https://www.scopus.com > Acesso em: 11 agosto 2017.

MÉNDEZ, J.A. e GONZÁLEZ, E.J. Implementing motivational features in reactive blended learning: Application to an introductory control engineering course. IEEE Transactions on Education, Vol. 54, 2011, p. 619-627. Disponível em: https://www.scopus.com > Acesso em: 11 agosto 2017.

MOORE, Michael. KEARSLEY, Greg. Teoria e Conhecimento da Educação a Distância. In MOORE, Michael. KEARSLEY, Greg. Educação a Distância Uma visão Integrada. Tradução Roberto Galman. São Paulo: Cengage Learning, 2010, p. $235-252$.

MORÁN, José. Mudando a educação com Metodologias Ativas. In SOUZA Carlos Alberto de, MORALES Ofelia Elisa Torres (org.). Coleção Mídias Contemporâneas. Convergências Midiáticas, Educação e Cidadania: aproximações jovens. PG: Foca Foto-PROEX/UEPG. Vol. II, 2015, p. 15-33.

REISSLEIN, J., SEELING, P. e REISSLEIN, M. Integrating emerging topics through online team design in a hybrid communication networks course: Interaction patterns and impact of prior knowledge. Internet and Higher Education, Vol. 8, 2005, p. 145165. Disponível em < https://www.scopus.com > Acesso em: 11 agosto 2017. 


\section{CRIAR EDUCACÃ̃̃}

SERDYUKOV, P. Does online education need a special pedagogy? Journal of

Computing and Information Technology. Vol 23, 2015, p. 61-74. Disponível em: < https://www.scopus.com > Acesso em: 11 agosto 2017.

SWART, A.J. Distance Learning Engineering Students Languish Under ProjectBased Learning, But Thrive in Case Studies and Practical Workshops. IEEE Transactions on Education, Vol. 59, 2016, p. 98-104. Disponível em < https://www.scopus.com > Acesso em: 11 agosto 2017.

VARGAS, Rubem Mário Figueiró et al. Graduação em Engenharia Química a Distância: PUCRGS uma Experiência Pioneira no Brasil. Revista de Ensino de Engenharia, Vol. 25, n. 2, 2006, p. 43-52. Disponível em: < http://www.abenge.com.br > Acesso em: 20 setembro 2017.

VARGAS, $\mathrm{H}$. et al. A network of automatic control web-based laboratories. IEEE Transactions on Learning Technologies, Vol. 4, 2011, p. 197-208. Disponível em: $<$ https://www.scopus.com > Acesso em: 11 agosto 2017.

VILELA, André Luis da Mota. VILELA, Gilvânia Lúcia da Silva. LIMA, Emerson de Oliveira. Ensino a Distância para Cursos Presenciais de Engenharia: O Caso da Escola Politécnica de Pernambuco. Revista de Ensino de Engenharia, Vol. 35, n. 1, 2016, p. 45-56. Disponível em: < http://www.abenge.com.br > Acesso em: 20 setembro 2017.

WU, P. et al. Delivering construction education programs through the distance mode: Case study in Australia. Journal of Professional Issues in Engineering Education and Practice, Vol. 139, 2013, p. 325-333. Disponível em: < https://www.scopus.com > Acesso em: 11 agosto 2017.

Recebido em dezembro 2018

Aprovado em março 2019 